\title{
VIOLENCIA EN LAS RELACIONES AMOROSAS Y VIOLENCIA CONYUGAL: CONVERGENCIAS Y DIVERGENCIAS. REFLEXIONES PARA UN DEBATE
}

\author{
TATIANA SANHUEZA MORALES
}

\begin{abstract}
RESUMEN
El presente artículo es producto de una revisión bibliográfica que explora sobre ciertas particularidades de la violencia en las relaciones amorosas de adolescentes y la violencia conyugal en parejas adultas. A su vez, se presentan resultados atingentes enmarcados en una investigación exploratoria más amplia. ${ }^{1}$ En este artículo se recogen las opiniones de 48 adolescentes chilenos participantes en grupos de discusión — de ambos sexos y de diferentes clases sociales - . Tanto los resultados empíricos como la literatura examinada, permitirían sostener estar en presencia de un fenómeno diferente que plantea desafíos de orden teórico como en su abordaje.
\end{abstract}

PALABRAS CLAVE: ADOLESCENTES, RELACIONES AMOROSAS, VIOLENCIA

* Académica chilena del Departamento Trabajo Social, Facultad de Ciencias Sociales, Universidad de Concepción. Asistente Social, Doctorada en Servicio Social (Universidad Laval, Québec, Canadá). Magíster en estudios de Género y Cultura mención Ciencias. Sociales (Universidad de Chile). Diplomada en Estudios de la Mujer (Universidad de Concepción). E-Mail: tsanhueza@udec.cl.

1 Investigación exploratoria-descriptiva con un enfoque multimetodológico, realizado en el marco de mis estudios de Doctorado en Servicio Social, Universidad Laval, Quebec, Canadá, denominada: «Representaciones de la violencia en las relaciones amorosas en adolescentes chilenos(as)». En este artículo nos referiremos particularmente a relaciones amorosas heterosexuales. 


\title{
VIOLÊNCIA NOS RELACIONAMENTOS ROMÂNTICOS E VIOLÊNCIA CONJUGAL: CONVERGÊNCIAS E DIVERGÊNCIAS. REFLEXÕES PARA UM DEBATE
}

\begin{abstract}
RESUMO
O presente artigo é produto de uma revisão bibliográfica que explora sobre certas particularidades da violência nos relacionamentos românticos de adolescentes e a violência conjugal em casais adultos. Por sua vez, apresentam-se resultados relacionados no contexto de uma pesquisa exploratória mais ampla. Neste artigo se reúnem as opiniões de 48 adolescentes chilenos participantes em grupos de discussão - de ambos os sexos e de diferentes classes sociais-. Tanto os resultados empíricos quanto a literatura examinada, permitiriam afirmar estar na presença de um fenômeno diferente que apresenta desafios tanto no teórico quanto em sua abordagem.
\end{abstract}

\author{
PALAVRAS CHAVE: ADOLESCENTES, RELACIONAMENTOS \\ ROMÂNTICOS, \\ VIOLÊNCIA
}

\section{VIOLENCE IN LOVE RELATIONSHIPS AND DOMESTIC VIOLENCE: CONVERGENCES AND DIVERGENCES. REFLECTIONS FOR A FUTURE DISCUSSION}

\begin{abstract}
The present article results from a bibliographical review of a number of particular aspects of violence in love relationships of teenagers and in domestic violence in adult couples, displaying relevant results in the context of a wider exploratory investigation. Opinions from 48 Chilean teenagers, of both sexes and from different social stratum, participating in discussion groups are gathered. Both the empirical results obtained and the reviewed literature are sufficient to argue the presence of a different phenomenon that set theoretical and practical challenges.
\end{abstract}

KEY WORDS: TEENAGERS, LOVE RELATIONSHIPS, VIOLENCE 


\section{INTRODUCCIÓN}

LA VIOLENCIA EN LAS relaciones amorosas en jóvenes, particularmente en adolescentes, ha sido un fenómeno largamente olvidado al estudiar otras formas de violencia en las relaciones íntimas (violencia conyugal, violencia intrafamiliar, maltrato infantil). Después de la primera investigación realizada por Makepeace (1981), quien demostró la existencia de la violencia en las relaciones amorosas en estudiantes universitarios estadounidenses. Diversos estudios han demostrado que la violencia física y la violencia psicológica forman parte de un número no desestimable de relaciones de parejas en este grupo etario. Sin embargo, la falta de consensos en su definición, las diferencias en cuanto a metodología, muestras poblacionales y estrategias de análisis, exponen una variabilidad en la prevalencia de la problemática. Como indican Shorey, Cornelius y Bell (2008) entre un $20 \%$ a un $37 \%$ de parejas jóvenes han vivido violencia física, lo que aumentaría al considerar la violencia psicológica hasta un $90 \%$.

En Chile, las primeras investigaciones sobre el fenómeno comienzan en la década de los 90 cuando la primera encuesta de juventud (Instituto Nacional de la Juventud, INJUV, 1994) informa de la existencia de este tipo de violencia en las relaciones amorosas sostenidas por jóvenes y adolescentes. ${ }^{2}$ Luego, en 1997 un estudio realizado por Aguirre e Infante vendría a confirmar los resultados precedentes en dos aspectos: primero, la existencia de la problemática en la población juvenil y, en segundo lugar, diferencias de género en donde -en comparación con los hombres jóvenes - un mayor porcentaje de violencia física sería ejercida por las mujeres jóvenes. ${ }^{3}$ Estudios a nivel internacional han profundizado en este aspecto (diferencias de género), lo que resulta un punto de partida interesante para establecer ciertas distancias en relación a la tendencia expuesta por diversos estudios, dirigidos a la población adulta, que documentarían que son las mujeres las principales víctimas. ${ }^{4}$

2 De una muestra de 3.792 jóvenes y adolescentes, un 10,2\% señalaba la presencia de violencia física y un $24,6 \%$ de violencia psicológica.

3 Hombres jóvenes denunciaban en un 13,9\% la presencia de violencia física en sus parejas en comparación con un $7.1 \%$ de las mujeres (INJUV, 1994).

4 Ver Encuesta sobre «Victimización por violencia intrafamiliar y delitos sexuales» de la División de Seguridad pública del Ministerio del interior (2012); Sistema AUPOL de Denuncias de Violencia intrafamiliar de Ca- 
Coherente con lo anterior, el componente etario jugaría un rol significativo puesto que diversos estudios establecerían que a edades más tempranas la violencia experimentada por los(as) sujetos sería menor. ${ }^{5}$ La violencia en sujetos de menor edad se caracterizaría por una mayor similitud entre ambos géneros y a medida que aumenta la edad se expondrían diferencias significativas respecto de la violencia informada por mujeres como por hombres adultos (ver sexta encuesta de juventud, INJUV, 2010).

En Chile, la mayoría de los datos existentes hacen referencia a estudios generales sobre juventud donde hay algunas preguntas sobre violencia (Encuestas de juventud, INJUV) o estudios de prevalencia de la violencia en donde se pueden analizar los datos por grupos de edad. Sin embargo, en los últimos trece años diversos estudios han intentado profundizar sobre las experiencias y percepciones de «la violencia en el pololeo» desde el punto de vista de los propios jóvenes (Servicio Nacional de la Mujer (SERNAM), 2003; DOMOS, 2010; SERNAM 2010b), demostrando la importancia e interés por conocer una problemática que existe, pero que poco se sabe de ella.

En el plano de la legislación, la invisibilidad de la violencia que ocurre en las relaciones amorosas, particularmente de adolescentes, se refleja en la actual Ley $\mathrm{N}^{\circ} 20.066$. Esta sanciona la violencia que ocurre en la familia, exclusivamente entre personas con un vínculo matrimonial; que tengan un vínculo por consanguineidad o por afinidad; aquellas que conviven y las ex-parejas con un hijo(a) en común. ${ }^{6}$

Lo cual deja prácticamente fuera a $\operatorname{los}($ as) adolescentes quienes, en su mayoría no están casados(as), no conviven y no tienen

rabineros de Chile (2005-2013) y Registro de femicidios íntimos elaborado por SERNAM (2014).

5 Lo que es corroborado por los resultados de INJUV (2012) donde en base a una muestra de 8.352 jóvenes, el $10 \%$ de adolescentes entre 15 y 19 años.

6 «...todo maltrato que afecte la vida o la integridad física o psíquica de quien tenga o haya tenido la calidad de cónyuge del ofensor o una relación de convivencia con él; o sea pariente por consanguinidad o por afinidad en toda la línea recta o en la colateral hasta el tercer grado inclusive, del ofensor o de su cónyuge o de su actual conviviente. También habrá violencia intrafamiliar cuando la conducta referida en el inciso precedente ocurra entre los padres de un hijo común, o recaiga sobre persona menor de edad, adulto mayor o discapacitada que se encuentre bajo el cuidado o dependencia de cualquiera de los integrantes del grupo familiar». (Ley de violencia intrafamiliar de Chile $\mathrm{N}^{\circ} 20.066$, artículo 5). 
hijos(as). ${ }^{7}$ De este modo, centrar el fenómeno en el contexto familiar impediría regular la violencia ocurrida en relaciones de parejas que se encuentran fuera de ese ámbito.

Sin embargo, ciertos avances en materia legal dan cuenta justamente de esta invisibilidad de la que hablabamos. Así, si bien en el marco de la Ley de Femicidio en Chile Ley №20.480 de 2010, se consignan femicidios solo aquellos perpetrados por cónyuges, convivientes o ex parejas, desde el año 2012 «...por decisión del Circuito de Femicidio, ${ }^{8}$ se optó por incluir en las estadísticas solo los femicidios de pareja, que incluye a todas las parejas cualquiera sea su vínculo (incluso novios o pololos) y también contempla aquellos que sin ser pareja tienen hijos en común» (red Chilena contra la violencia hacia las mujeres, 2014:60).

Si consideramos que la comprensión de un fenómeno puede influir en el modo de abordarlo (Lesieux, Rinfret-Raynor y Brodeur, 2014; Smedslund, 2014), en materia de políticas públicas, específicamente respecto de acciones en materia de prevención, las orientaciones dadas por el «Plan Nacional de Violencia Intrafamiliar de Noviembre 2012-Diciembre 2013» (aún vigente en Chile), define la violencia en la pareja o doméstica como «toda forma de maltrato o abuso sea físico, psicológico-emocional, sexual o económico que tiene lugar en la pareja sin importar la forma del vínculo...» (SERNAM, 2012:11). Sin embargo, cuando se describe la violencia por grupo etario, se hace considerando la violencia intrafamiliar contra las mujeres (como un grupo homogéneo sin distinguir especificidades por edad), contra niños y niñas y contra los(as) adultos(as) mayores. Así mismo, cuando se exhiben las consecuencias de la violencia intrafamiliar según las etapas de vida se describen los efectos en el desarrollo de la adolescencia en base a la experiencia de violencia en su familia. Entonces, los(as) adolescentes no son vistos como sujetos que establecen relaciones amorosas y que pueden vivir violencia, porque la violencia es concebida dentro de un contexto familiar.

7 Un $8 \%$ de adolescentes entre 15 a 19 años declara tener un hijo(a), siendo su estado civil solteros(as) (INJUV, 2012).

8 Instancia de articulación de diferentes instituciones que tiene como objetivo garantizar la protección y atención integral de víctimas directas e indirectas de femicidio. Dicha instancia está compuesta por: Carabineros de Chile a través de la Dirección de protección policial de la familia (Diprofam), Servicio Nacional de la Mujer, Servicio Nacional del Menores y el Ministerio del Interior y Seguridad Pública. 
En el mismo sentido que las ideas precedentes, al considerar uno de los objetivos específicos de dicho Plan, a saber: «Desarrollar acciones intersectoriales para prevenir la violencia basada en el género, particularmente la VIF desde la primera infancia y a lo largo de las diversas etapas de la vida» (SERNAM, 2012:28), es posible deducir que este instrumento tiene en cuenta la violencia vivida en la etapa de la adolescencia, pero como una problemática familiar.

No obstante la falta de visibilidad de los(as) adolescentes como sujetos más allá de la familia, el Plan citado considera acciones de prevención ${ }^{9}$ para prevenir la violencia en el pololeo y la prevención de la violencia sexual. Estrategias situadas principalmente en establecimientos escolares.

Si consideramos la adolescencia como la etapa de inicio de las relaciones amorosas (Cloutier y Drapeau, 2008; Breinbauer y Maddaleno, 2005) y estimando que la violencia vivida en este período pudiese ser un predictor de la violencia ocurrida en relaciones adultas, nos parece pertinente adentrarnos en los aspectos que la distinguen en relación a la violencia conyugal de manera de contribuir en el debate sobre lo que conocemos de la problemática y sus implicancias en el abordaje.

El presente artículo se compone de dos partes: En la primera, se realiza una revisión bibliográfica que recoge estudios nacionales como internacionales. A partir de los cuales se expondrán convergencias y divergencias respecto de las relaciones amorosas y de la violencia en parejas de adolescentes y en parejas adultas. En segundo lugar, se presentará el punto de vista de los(as) adolescentes en torno a estas diferencias y la información que poseen respecto de acciones de prevención destinadas a ellos(as). Lo anterior, con el objeto de abrir y enriquecer el debate en torno a la necesidad de visibilizar la violencia en las relaciones amorosas de adolescentes y jóvenes que considere sus particularidades para de esta manera comenzar a pensar en formas pertinentes de abordaje.

9 Impulsadas por el Servicio Nacional de la Mujer, el Instituto Nacional de la Juventud, el Ministerio de Educación y la DIPROFAM de Carabineros de Chile, entre las que podemos mencionar: la realización de campañas en los medios de comunicación, talleres de prevención en liceos, formación de monitores jóvenes, entre otros. 


\section{Metodologia}

Para el análisis bibliográfico se trabajó sobre la base de estudios chilenos dirigidos a la población juvenil respecto de la violencia en el pololeo. Dichos estudios mayoritariamente pretendían conocer las percepciones y puntos de vista de adolescentes frente a la problemática. Además se escogieron artículos internacionales, que por un lado describían la violencia vivida por adolescentes y jóvenes, y otros que comparaban la violencia en diferentes tipos de relaciones. Respecto de los datos empíricos, se exponen las opiniones de 48 adolescentes de ambos sexos quienes participaron en grupos de discusión no mixtos en la primavera de 2014. Como ya hemos señalado se expondrán algunos resultados pertinentes al objeto de este artículo.

Para acceder a los(as) sujetos de investigación se contactaron siete establecimientos educacionales públicos y privados de la Provincia de Concepción. Se solicitó el asentimiento firmado por parte de los(as) adolescentes interesados(as) en participar del estudio así como un consentimiento parental. No existió retribución económica y se aseguró la confidencialidad de los testimonios. Para asegurar la confiabilidad de la información se transcribieron en su totalidad los audios. Para la codificación se utilizó el programa computacional NVivo. Se realizó análisis de contenido.

\section{a) Pareja y violencia: similitudes y diferencias en adolescentes y adultos}

Dos grandes ejes se han organizado para exponer algunas convergencias y divergencias en ambos grupos. En torno a aspectos en las relaciones amorosas y aquellos asociados a este tipo de violencia. Tres enfoques resultan pertinentes para el análisis: a) el enfoque psicosocial, que considera la adolescencia como una etapa vital en donde se consolidan diferentes procesos — cognitivos, biológicos y socialespertinentes para conceptualizar la transformación del sí mismo(a); b) la noción de generación que exhibe la estrecha relación entre la construcción del sujeto(a) y su contexto histórico. Y un tercer enfoque es c) la perspectiva de género que nos permite concebir la masculinidad y la feminidad como construcciones socioculturales dinámicas, así como analizar cuestiones relativas al poder, estereotipos y la posición social hombre/mujer. 
i) Primer eje: aspesctos a considerar en las relaciones amorosas para un análisis comparado

En base a la literatura examinada distinguimos tres elementos asociados a las relaciones amorosas que permitirían exponer similitudes y diferencias en las experiencias de adolescentes y adultos: en torno a los(as) sujetos; la cualidad de las relaciones y el contexto en que éstas se desarrollan.

\section{...Sujetos(as) en relación amorosa...}

Una primera constatación a plantear es la divergencia relacionada a la etapa de vida en la que se encuentran ambos grupos y las tareas a resolver, en donde los(as) adolescentes estarían expuestos a conflictos que los(as) adultos en general ya atravesaron. Si los(as) primeros(as) se concentran en los estudios; adaptación a los cambios de orden físico, social y biológico; construcción de identidad (en donde el género juega un rol importante); afirmación de la autonomía, discernir aspectos vocacionales, entre otros. (Cloutier et al., 2008; Breinbauer et al., 2005), los(as) segundos(as), se enfrentarían a la experiencia de un trabajo remunerado, la formación de una familia, crianza de hijos(as), entre otros.

En relación a la vivencia amorosa en sí, la «juventud» de los(as) adolescentes estaría asociada a una menor experiencia si se la compara con la de los(as) adultos. Este nivel de experiencia en el plano amoroso asociado a la etapa de vida nos expondría una segunda divergencia: si los(as) adolescentes están abocados a dar inicio y experimentar en este plano, los(as) adultos, por lo general se encontrarían en la etapa de consolidación o de establecer relaciones con una mayor formalidad. ${ }^{10}$

Un tercer elemento expone la posición de dependencia y la resolución de problemas que atañe al período de la adolescencia. El hecho que un $94 \%$ de adolescentes viva con sus padres y un $81 \%$ estudie (INJUV, 2012), significa que existe una fuerte vinculación - económica, legal, emocional, de formación - respecto de los(as) adultos. Así, a pesar de la importancia que asume el grupo de pares durante este período (Ar-

10 En Chile el promedio de edad al momento de casarse en hombres es de 35 años y de mujeres de 32 años (Instituto Nacional de Estadísticas, 2011). En concordancia, el $100 \%$ de los(as) adolescentes (15 a 19 años) participantes declara estar soltero(a) (INJUV, 2012). 
riaga y Foshee, 2004; Ismail, Berman y Ward-Griffin, 2007; Chung, 2005; Próspero, 2007) y el proceso de autonomía que se intensifica en la adolescencia, es posible sostener que los(as) adultos (todavía) juegan un rol activo en cuanto a la protección, orientación, educación y prevención frente a las problemáticas adolescentes. Esto no quiere decir que los(as) adolescentes no sean los(as) principales actores en la resolución de sus problemas, sin embargo, los(as) adultos también están involucrados en los problemas «privados» que los(as) adolescentes podrían estar viviendo (Vézina y Hébert, 2007).

\section{...Cualidad de la relación amorosa...}

Una convergencia identificada respecto de la cualidad de este tipo de relación es la intimidad. Esta cualidad se traduce en la exclusividad que pudiese caracterizar dicha relación; el tiempo destinado; la participación activa de los miembros de esa relación íntima; la información intercambiada; la posible existencia de vulnerabilidad emocional así que la posibilidad de influenciar altamente al otro u otra; los planos que involucraría dicha relación íntima —sexualidad, hijos(as), económico, etcétera - y los factores de estrés que pudiesen afectar a este tipo de relaciones y no a otro tipo de relaciones - de amistad o con colegas de trabajo, compañeros(as) de curso, conocidos(as) o familiares- (Carlson, 1987).

No obstante esta concordancia, se plantean divergencias importantes entre adultos y adolescentes respecto de la calidad o nivel de dicha intimidad, ya que no todas las relaciones establecidas en la adolescencia logran un alto nivel de intimidad antes de su ruptura. Si bien sus relaciones amorosas podrían estar caracterizadas por una gran intensidad y compromiso emocional, las dimensiones de compromiso son limitadas en comparación a las de adultos (legales, económicos, familiares, sexuales, entre otros).

Por otro lado, la variabilidad en las relaciones amorosas podría influir en la intimidad y en las manifestaciones de la violencia. La literatura constata que las parejas adultas tienen menos variedad en comparación con las relaciones establecidas por adolescentes. Así, es posible identificar el matrimonio y la convivencia o cohabitación como aquellas relaciones comúnmente establecidas por los primeros (Carlson, 1987; Makepeace, 1989; Stets y Straus, 1989; Sugarman y Hotaling, 1989). Es importante precisar la figura de las «ex-parejas» puesto que a pesar de la inexistencia de una relación, es posible que 
permanezca un vínculo, no de naturaleza amorosa por cierto, en donde posterior a una separación matrimonial o de convivencia los exmiembros podrían tener aún muchos temas a resolver (cuidado y educación de hijos(as), asuntos de dinero, decisiones a propósito de los bienes, vínculos familiares, etcétera). Así, la noción de «relación» en esta situación no estaría solamente restringida a la «cohabitación» y al vínculo amoroso. ${ }^{11}$

En el caso de las relaciones amorosas de adolescentes la variedad sería mayor: el «pololeo» ${ }^{12}$ que puede ser de corta duración (entre un mes a cuatro meses) o de larga duración (más de seis meses); el «andar», fase previa a una relación de mayor compromiso en la cual se está en proceso de conocer al otro(a); los encuentros de una tarde, los amigos(as) sexuales, entre otras. Estas dos últimas prácticas ciertamente difieren de una relación amorosa «tradicional», sin embargo, estamos frente a un escenario en donde dos personas realizan un intercambio emocional en un grado y dinámica que pudiese sentar las bases para que ocurriese alguna situación de conflicto o de violencia y en donde el riesgo es justamente invisibilizar este tipo de prácticas establecidas fundamentalmente en la adolescencia. En este sentido, Makepeace (1989) documenta la ocurrencia de situaciones de violencia en una primera salida y la consecuente minimización e invisibilización al no denunciar este tipo de hechos por quienes la vivieron debido a no enmarcarse dentro de una «relación».

Esta mayor variabilidad podría volver más compleja la definición de «relación amorosa», como a su vez podría dificultar la comprensión de la violencia ocurrida entre dos personas que no tienen una relación formalmente establecida pero que si se frecuentan emocionalmente. Otra dimensión de esta variabilidad es «el romance virtual», conocido entre los(as) jóvenes como ciberpololeo ${ }^{13}$ así como el sexo

11 La ley de violencia intrafamiliar chilena 20.066, considera la violencia ocurrida en ex-parejas con un hijo(a) en común, donde reconoce, por un lado, la continuidad de un vinculo mas allá de la existencia de una relación amorosa y por otro, de esta manera reconoce el tiempo posterior a un quiebre emocional como un escenario de alto riesgo para experimentar conflictos y violencia.

12 Expresión típica chilena para denominar las relaciones amorosas sin convivencia o matrimonio. El pololeo implica un mayor compromiso que frecuentarse y un menor compromiso que noviazgo, en este último los miembros están comprometidos a contraer matrimonio.

13 Término que congrega el neologismo ciber con el chilenismo pololeo. 
virtual (Cárcamo y Nesbet, 2008). Ambas prácticas se reconocen propias de las generaciones actuales en comparación con las generaciones precedentes. Autores señalan que debido a la inmediatez del medio y al carácter confidencial de la comunicación, podrían influir en los estilos actuales de relaciones amorosas así como exponer a ciertos riesgos a sus usuarios(as).

Finalmente, la literatura expone diferencias en torno a los conflictos que viven las parejas. Si para las parejas adultas, los hijos(as), el dinero, el sexo, los aspectos domésticos y las actividades sociales serían las fuentes de conflicto más recurrentes. Para los(as) adolescentes, además del sexo, los celos y el consumo de alcohol (Carlson, 1987; Sugarman et al., 1989; Riggs y O'Leary, 1989), se mencionan: la confianza en el otro(a), el tiempo invertido juntos, las salidas, valores y hábitos de vida (Fernet, Hébert, St-Hilarie, Blais, Gascon y Manseau (2014). También «Facebook» y las llamadas «redes sociales» son vistas como una importante fuente generadora de tensiones al interior de las relaciones amorosas de adolescentes (DOMOS, 2010).

\section{...Contexto de los(as) sujetos y sus relaciones amorosas...}

Considerar adultos y adolescentes como sujetos(as) situados(as) nos remite al contexto en el cual estos(as) se desenvuelven. En este sentido, el concepto de generación nos parece útil para establecer distinciones en las relaciones de ambos grupos. Siguiendo a Abrams (1982) — citado en Leccardi y Feixa, 2011—, la generación remite al período de tiempo durante el cual se construye una identidad sobre la base de los recursos y significados que socialmente e históricamente se encuentran disponibles. Para lo cual «la presencia de acontecimientos que rompen la continuidad histórica y marcan un antes y un después en la vida colectiva; y por otra parte, el hecho de que estas discontinuidades sean experimentadas por miembros de un grupo de edad en un punto formativo en el que el proceso de socialización no ha concluido, por lo menos en sus fases más cruciales...» (Leccardi et al, 2011:17) serían los componentes fundamentales para que surja el vínculo generacional. ${ }^{14}$

14 Un factor importante a considerar - como un acontecimiento que rompe la continuidad histórica en Chile - dice relación con el retorno a la democracia en 1990 y la implementación de políticas públicas tendientes a promover la igualdad de género. 
Según Cloutier et al. (2008:7) «... les adolescents d'aujourd'hui ne vivent pas comme ceux d'autrefois. Les jeunes sont directement influencés par les contextes dans lesquels ils se développent». ${ }^{15}$ Así, los(as) adolescentes de hoy viven nuevas condiciones caracterizadas por sociedades que en los últimos decenios han experimentado cambios y transformaciones a nivel global (Giddens, 1995; Castells, 2000), lo que se ha llamado el paso de una sociedad industrial a una sociedad de información o del conocimiento, donde los procesos de individuación ${ }^{16}$ caracterizarían la trayectoria de individuos así que las relaciones de género.

No obstante los cambios experimentados por la sociedad chilena, es posible sostener estar en presencia de un contexto mixto que refleja leves variaciones en su ordenamiento de género dando continuidad a relaciones desiguales entre mujeres y hombres. Lo anterior es expuesto en un estudio realizado por el Programa de Naciones Unidas para el Desarrollo (PNUD), 2010) que describe un contexto chileno caracterizado por representaciones de género machistas ${ }^{17} \mathrm{y}$ autoritarias; violencia hacia las mujeres (que respondería a estas representaciones, así como al surgimiento de una violencia motivada justamente por los cambios en las relaciones de género) $;{ }^{18}$ discriminación hacia las mujeres en el mercado del trabajo; mínimos cambios en la distribución de las actividades domésticas y cuidado de niños(as), ${ }^{19}$ subrepresentación

$15 \ll$ «..los adolescentes de hoy, no viven como los de otros tiempos. Los jóvenes son directamente influenciados por los contextos en los cuales ellos se desarrollan» (traducción de la autora).

16 El término hace referencia a la construcción de proyectos de identidad de las personas según sus propias elecciones dejando de lado los mandatos institucionales y su posición en la sociedad (PNUD, 2010).

17 El término «machismo» designa la tendencia de ciertos hombres o mujeres a privilegiar de manera exacerbada y exclusiva la virilidad de los hombres y de creer que las mujeres serían inferiores en todos los dominios o en todos los dominios prestigiosos, justificando que ellas sean destinadas a las tareas subalternas (PNUD, 2010).

18 Fenómeno denominado por Montecino (2007) como «neomachismo» para explicar las nuevas formas de machismo frente a la pérdida de privilegios masculinos (Citado en PNUD, 2010).

19 En el segmento juvenil, al analizar el tiempo destinado al «trabajo doméstico y de cuidado de personas no remunerado» se observan diferencias importantes por sexo: las jóvenes dedican a este trabajo tres veces la proporción de tiempo que los jóvenes $(31,4 \%$ y $10,6 \%$ respectivamente. Lo que en tiempo promedio semanal equivale a: 22,8 horas y 
femenina en las élites de poder económico, político, simbólico y social; $y$, ausencia de los hombres en las políticas públicas y en los cambios ligados a las relaciones de género. Esta continuidad en la posición de subordinación de las mujeres en relación a los hombres influiría de manera particular en las diferentes generaciones. En el caso de los(as) adolescentes, debido al proceso de construcción de identidad y autodefinición en el que se encuentran.

Por otro lado, una divergencia entre ambas generaciones - expuesta en la literatura y que también alude al contexto- dice relación con el uso de la tecnología en las prácticas juveniles. ${ }^{20}$ Dicho factor se enmarca en la sociedad de la información de la que hacíamos referencia, en donde las tecnologías facilitarían la creación, distribución y manipulación de la información, jugando un rol importante en las actividades sociales, culturales y económicas. La «era informacional» como un nuevo paradigma que organiza esferas diferentes - relaciones interpersonales, formas laborales o modos de construir la identidad-, conllevaría un cambio de mentalidad, desde una tradicional a una moderna así como la idea de una sociedad más igualitaria y más justa (Castells, 2000).

Si en el proceso de construcción de identidad los(as) adolescentes exacerban la búsqueda de espacios, entonces este proceso iría de la mano del uso de las nuevas tecnologías. Facebook, wathsapp, twitter, fotolog o blog, entre otras, llamadas comúnmente «redes sociales», jugarían un papel importante en las formas de comunicación entre la población juvenil. «Buscar información», «enviar y recibir mail», «chatear» y «usar facebook», serían actividades cotidianas asociadas al uso de internet (INJUV, 2010). Para algunos autores, la importancia de estas prácticas en la cotidianeidad juvenil podría tener repercusiones en los procesos de socialización, en donde el contexto tecnológico actual vería desarrollado «... al máximo la abstracción de las relaciones sociales; en otras palabras las relaciones cara a cara o interpersonales, disminuyen o son cada vez más innecesarias» (Cárcamo et al., 2008:40). ${ }^{21}$ Para otros

7,5 horas comparativamente (Sexta encuesta de juventud, 2010).

20 Mientras el $29 \%$ de las personas mayores de 18 años usa habitualmente internet, en los(as) adolescentes de entre 14 y 17 años esta cifra alcanza el 72\% (PNUD, 2006).

21 Esto se produce por lo que Giddens (1990) denomina «desanclaje», la capacidad de la modernidad para disociar el tiempo del espacio (citado en Cárcamo y Nesbet, 2008). 
autores, los(as) jóvenes utilizarían las nuevas tecnologías para mantener y profundizar las relaciones que ya tienen cara a cara. El uso de estas no reemplazaría las relaciones directas así como tampoco implicaría un aislamiento por parte de los(as) sujetos(as), por el contrario, generaría cambios positivos, por ejemplo, en las relaciones con los(as) amigos(as) (De Laire, 2001; Gil, 2003, citados en Cárcamo et al., 2008; PNUD, 2006).

Finalmente, la influencia de los(as) amigos(as) y la necesidad de aprobación del grupo de referencia serían expuestos como factores relevantes en las experiencias de jóvenes. La literatura ha documentado al grupo de pares como un elemento de contexto que expone ciertas diferencias entre adolescentes y adultos y que podría tener repercusiones en las experiencias y uso de la violencia (Arriaga et al., 2004; Ismail et al., 2007; Chung, 2005; Próspero, 2007).

ii) Segundo eje: componentes de la violencia:

similitudes y diferencias en adolescentes y adultos

En este eje analizaremos tres elementos: dinámica de la violencia (que incluye cronicidad, direccionalidad, prevalencia y manifestaciones); significaciones de la violencia y factores de riesgo asociados a la problemática.

\section{...Dinámica de la violencia...}

La literatura expone la necesidad de comprender la violencia en las relaciones íntimas en términos dinámicos; es decir, esta no ocurriría de manera aislada tampoco sería estática. Hablaríamos de un proceso complejo que es parte de la relación asimétrica que se establece entre un hombre y una mujer a través de un vínculo violento que continúa y se acrecienta en el tiempo. Para caracterizar la dinámica repetitiva de la violencia conyugal en una primera etapa fue ampliamente utilizado el concepto de «ciclo de violencia» (Walker, 1979). Compuesto de tres fases que se sucedían en el tiempo: fase de tensión, fase de agresión y fase de reconciliación o «luna de miel». En base a este modelo la tradición feminista describía la dinámica de la relación en las parejas adultas, exponía como el agresor mantenía el control sobre su víctima, donde la mujer es a menudo la principal víctima y el hogar un lugar más peligroso para ella que para el hombre (Loseke y Kurz, 2005). 
Retomando ciertas críticas dirigidas hacia este modelo que no daría cuenta de algunas experiencias de mujeres que vivían violencia, surge la «Rueda de poder y control». Elaborado por mujeres golpeadas participantes de un proyecto de intervención («El Modelo de Duluth»). ${ }^{22}$ Dicho modelo utilizado por el feminismo pone en evidencia la ideología patriarcal que sustenta la violencia hacia las mujeres en contexto doméstico y enfatiza la utilización de múltiples estrategias de control ejercidas por hombres agresores, ${ }^{23}$ siendo la violencia masculina un comportamiento aprendido que refuerza la desigualdad y asimetría en la relación.

Ambos modelos - aunque diferentes - sostienen que la duración prolongada de una relación de violencia permitiría hablar de cronicidad de la violencia, lo que refleja su carácter ascendente o comúnmente llamado «escalada de la violencia». Si consideramos la corta duración que caracteriza las relaciones amorosas de adolescentes, se podría pensar que ambos modelos han sido diseñados desde las experiencias adultas para, describir en definitiva, dinámicas asociadas a relaciones de larga duración en donde hay diferentes planos comprometidos (económico, hijos(as), convivencia, entre otros). Aunque jóvenes y adolescentes mantengan relaciones de mayor duración ambos modelos reproducen una dinámica representativa de la violencia conyugal.

Podríamos inferir entonces que la corta duración de las relaciones de adolescentes sería un factor que dificultaría la existencia de una cronicidad de la violencia o que al menos problematizaría describir esta dinámica (Riggs et al., 1989). Respecto de esto, autores recomiendan focalizarse en los problemas de las relaciones de adolescentes o en los factores de estrés para comprender mejor sus experiencias de violencia, más que sobre sus dinámicas de pareja (De Maris, 1987; Makepeace, 1989; Shorey et al., 2008).

Si la duración de la relación puede influir en la dinámica de la violencia o en su cronicidad, es posible preguntarse si también pueden influir en la gravedad de la violencia (qué tipo de violencia se usa y

22 Fundado por Ellen Pence y Michael Paymar. Citados por Johnson (1995).

23 Abuso físico, abuso sexual, intimidación, abuso emocional, aislamiento, desresponsabilización, negar, minimizar, culpar, manipular a través de los niños, privilegio masculino, abuso económico, coerción y amenazas. 
con qué frecuencia) y en su direccionalidad (desde quién y hacia quién se ejerce violencia).

En relación a la gravedad - aunque los estudios analizados no sean comparables en cuanto a muestras e instrumentos utilizados- es posible indicar tanto convergencias como divergencias entre ambos grupos. Ciertos autores indican que la violencia vivida por adultos tendería a ser más severa que la violencia vivida por adolescentes, lo que es coherente con lo expuesto por algunos(as) autores respecto de la correlación entre el aumento de la edad, la formalidad de la relación amorosa y la severidad de la violencia (Henton, Cate, Koval, Lloyd y Christopher, 1983; Roscoe y Benaske, 1985; Stets et al., 1989; Roscoe y Callahan, 1985; Carlson, 1987; Sugarman et al., 1989; Vézina et al., 2007; Hird, 2000; Makepeace, 1989).

Otros autores sostienen que en las relaciones amorosas de adolescentes también pudiesen ocurrir manifestaciones graves de violencia (Barter, McCarry, Berridge y Evans, 2009; Molidor y Tolman, 1998; Lehrer, Lehrer y Zhao,2010). Lo que se confirmaría al considerar que el 10,2\% de los femicidios ocurridos en 2010 en Chile, el autor fue el pololo y en el 9,7\% se trató del ex-pololo (SERNAM, 2010a). Así mismo, en las estadísticas recogidas por DOMOS (2010) respecto del período 2008 y 2009 , el $25,4 \%$ de las víctimas de femicidio fueron menores de 30 años. A su vez, el estudio realizado por la Red Chilena Contra la Violencia Doméstica y Sexual (2014) sobre femicidio en Chile indica que «Las mujeres que son asesinadas por razones de género son cada vez más jóvenes. El promedio de edad de las mujeres ha mostrado un descenso, desde 38 años en 2010 a 35 años en 2011 y 2012» (p.45). Según este Informe, la violencia femicida afecta a las mujeres en cualquier momento de su vida, es lo que se ha llamado el «continuo de la violencia»; es decir, en todas las etapas de vida, las niñas, adolescentes y mujeres viven violencia en sus múltiples manifestaciones y que el extremo de esta violencia está representada por el femicidio.

Respecto de la prevalencia, cuando se ha medido violencia física moderada en estudios dirigidos a la población general, ${ }^{24}$ la violencia, tanto en adultos como en adolescentes parece simétrica; ${ }^{25}$ es decir,

24 La mayoría de los estudios han utilizado la Conflict Tactics Scale (CTS) (Strauss, 1979) o la CTS modificada (Strauss et al, 1996).

25 Se habla de «simetría» de la violencia para exponer una tasa similar de violencia ejercida tanto por mujeres como por hombres hacia sus parejas (Strauss, 2005) y de «asimetría»cuando existen diferencias importantes 
tanto hombres como mujeres ejercerían la violencia en un porcentaje similar (Damant y Guay, 2005; Straus, 2005; Jonhson, 1995; Sugarman et al., 1989; Henton et al., 1983; O'Keefe y Treister, 1998; Foshee 1996). No obstante en este plano, ciertos estudios indicarían que las adolescentes ejercerían más violencia física moderada hacia su pareja (Barter et al., 2009; Wolfe, Scott, Reitzel-Jaffe, Wekerle, Grasley, Straatman, 2001; Molidor et al., 1998; Foshee 1996; Sears, Byers y Price, 2007, INJUV, 2012; Aguirre et al, 1997). Por el contrario, cuando la violencia sexual y la violencia física grave son medidas, las mujeres y las adolescentes son las principales víctimas de este tipo de violencia (Damant et al., 2005; Loseke et al., 2005; Gagné, Lavoie y Hébert, 1994; Barter et al., 2009; Molidor et al., 1998; Lehrer et al., 2010; Wolfe et al., 2001; Sears et al., 2007; O'Keefe et al., 1998; Shorey et al., 2008; Hird, 2000). Respecto de la violencia verbal y psicológica, los estudios constatan que tanto en parejas adultas como en parejas adolescentes, es el género masculino quienes se declaran las principales víctimas (Barter et al., 2009; Sears et al, 2007; Wolfe et al., 2001; INJUV, 2012).

Si revisamos las manifestaciones o los gestos de violencia utilizados en la pareja, también es posible exponer algunas diferencias entre adolescentes y adultos. Por ejemplo, en el plano físico, en parejas que cohabitan (adultas generalmente) se utilizaría el hogar para aislar a la víctima de su familia y redes más cercanas, lo que diferiría de las parejas adolescentes en donde no existe un lugar común de la pareja (cohabitación). Sin embargo, sí vivirían la experiencia de ser alejadas de sus amigos(as). En el ámbito psicológico, las mujeres adultas informarían recibir descalificaciones y amenazas graves que no solo las afectaría a ellas sino también involucraría la seguridad de los(as) hijos(as) así como de otros familiares. En el caso de las adolescentes, la manipulación sería experimentada en torno a su círculo de amigos(as) - al no tener hijos(as) o no estar «involucrada» la familia-. En cambio, la difusión, a través de redes sociales, de información que dañe su imagen, sería una manifestación común de violencia vivida en mujeres jóvenes más que en las generaciones de mujeres adultas (DOMOS, 2010).

entre ambos géneros, tanto en la severidad como en las consecuencias de la violencia, en donde las mujeres mayoritariamente serían las víctimas de ésta (Loseke y Kurz, 2005; Johnson, 1995). 
En el ámbito sexual, son las mujeres adultas quienes informan en mayor número ser víctimas de agresiones graves como acoso y violación de parte de su pareja. Por el contrario, los hombres adultos escasamente hacen referencia a una violencia recibida en este plano (Damant et al., 2005). Por su lado, en la generación de los(as) adolescentes ambos refieren ejercer y recibir gestos en este plano: ellos «presionarían o utilizarían la fuerza para tener un contacto sexual». Ellas, informan «dar un beso a la fuerza», «dar caricias o tocar en contra de la voluntad de su pareja» (Wolfe et al., 2001). Esta supuesta simetría es expuesta en INJUV (2012) en donde el 1\% de adolescentes de ambos sexos informa haber experimentado violencia sexual por parte de su pareja. Finalmente, en el plano económico, la literatura no menciona manifestaciones de este tipo violencia entre adolescentes y en el caso de adultos, son las mujeres quienes hacen mayor referencia a este tipo de experiencias: «destrucción de bienes materiales», «apropiación de su salario», «restricción económica» (Damant et al, 2005), así como «desvalorización del trabajo femenino», «la escasa participación de la mujer de decisiones sobre el destino de los recursos del hogar»o «el abandono de un trabajo a causa de la violencia que vive en el hogar» (SERNAM, 2008).

Si bien las consecuencias y su impacto en diversos ámbitos de la vida dependería de la severidad y cronicidad de la violencia. Los estudios documentan que mujeres adultas y las adolescentes serían las principales perjudicadas tanto en su salud física, mental, sexual y reproductiva, así como también se ven afectados los ámbitos laborales, familiares, estudios y vida social. Por otro lado, ellas, a causa de las consecuencias de la violencia usarían en mayor medida distintos servicios públicos (sanitarios, judiciales y sociales) (DOMOS, 2010). Lo que no significa que hombres y los adolescentes no tengan consecuencias producto de la violencia, sin embargo, la documentación existente plantea que la tasa sería más elevada para el género femenino (Damant et al., 2005; Loseke et al., 2005; Fernet, 2005; Sugarman et al., 1989; Vézina et al., 2007; Stets et al., 1989; Roscoe et al., 1985a; Roscoe et al., 1985b; O'Keefe et al., 1998) Por tanto, el género expondría convergencias entre las generaciones, así las mujeres y las adolescentes experimentarían a menudo los gestos más severos y las consecuencias más graves sobre tres planos de la violencia: violencia física, violencia psicológica y violencia sexual.

En cuanto a la direccionalidad, la literatura ha documentado ampliamente la unidireccionalidad ejercida de parte del hombre hacia la 
mujer, lo que Johnson (2008) ha denominado intimate terrorist y la violencia ejercida regularmente por la mujer como una forma de defensa violent resistance.

Por su parte, los estudios dirigidos a jóvenes expondrían una violencia caracterizada por la mutualidad, en donde - aunque la severidad no sería la misma - ambos ejercerían violencia hacia su pareja (INJUV, 2012; Vézina et al., 2007; SERNAM, 2010b).

\section{...Significaciones de la violencia...}

La literatura expone ciertas similitudes como diferencias ligadas al género cuando se refiere a las significaciones que los(as) sujetos elaboran de la violencia. Por su lado, mujeres adultas y las adolescentes informan el miedo como el sentimiento más frecuente y la autodefensa como una forma de reacción hacia la violencia ejercida por su pareja. En cambio hombres adultos y los adolescentes, ejercerían violencia comúnmente con el fin de dominar o intimidar a su pareja (Damant et al., 2005, Loseke et al., 2005; SERNAM, 2003). Si para el feminismo, el acento para explicar la violencia conyugal estaría puesto en los factores sociales y culturales (sistema patriarcal), en la asimetría de poder entre hombres y mujeres y en la aceptación social de la violencia en donde las mujeres serían las principales víctimas. Diversos estudios dirigidos a jóvenes discuten la pertinencia de este marco teórico para explicar la violencia en sus relaciones. En primer lugar, la violencia ejercida por parte de las jóvenes hacia sus enamorados (Riggs et al.,1989); en segundo lugar, las explicaciones dadas por algunas mujeres jóvenes, quienes subrayan que la autodefensa no sería la principal razón para usar violencia hacia sus pololos; y en tercer lugar, los motivos dados por ciertos hombres jóvenes quienes ejercerían violencia para evitar la escalada de violencia ejercida por sus parejas, donde el «terrorismo patriarcal» ${ }^{26}$ no sería la razón principal para ejercer la violencia masculina (Foshee, Bauman, Linder, Rice y Wilcher, 2007; Makepeace, 1989).

26 Concepto elaborado por Johnson (1995) para explicar la violencia ejercida por los hombres hacia sus parejas. Se trata de una forma de ejercer intencionalmente el control y el poder. El concepto contiene las raíces culturales e históricas de este tipo de violencia. Posteriormente el autor lo denomina «intimate terrorist». Existen otras tres tipologías descritas por el autor para identificar las diferentes formas de ejercer violencia y control en la pareja (ver Johnson, 2008). 
En el mismo orden de ideas, los estudios —en adolescentes y jóvenes - describen ciertos elementos ligados a la significación de la violencia que podrían establecer otras divergencias importantes respecto de los adultos: El primero, concierne al relativismo que envuelve la violencia para los(as) jóvenes; es decir, en algunas situaciones ciertos gestos no serían considerados violentos. Por ejemplo, el «sexo fuerte», en donde algunos actos en ese plano no serían interpretados como abusivos por los(as) adolescentes, sino actos consensuados en un contexto de experimentación (Lavoie, Robitaille et Hébert, 2000). Un segundo elemento, dice relación con el criterio para definir la violencia, los jóvenes la definirían según la intención; es decir, si existe el propósito de hacer daño el gesto sería considerado violencia y las jóvenes según el impacto, en donde si un acto provoca daño, miedo o dolor sería considerada violencia (Sears, Byers, Whelan y SaintPierre, 2006). Un tercer elemento expuesto por diversos estudios que confirma la propiedad subjetiva de la violencia por parte de los(as) adolescentes y jóvenes, es la noción de juego asociada a ciertos actos considerados tradicionalmente como violencia; por ejemplo: empujar, rasguñar, torcer un brazo, luchar, coquetear con alguien. (Lavoie et al., 2000; Foshee et al., 2007; Barter, 2009; Sears et al., 2006; Hird, 2000). Estos elementos exponen la importancia del contexto y de la interpretación dada por los(as) jóvenes a sus actos, pudiendo establecer ciertas diferencias con las significaciones de adultos.

Respecto de las razones entregadas por mujeres casadas para mantenerse en una relación de violencia, podemos inferir que difieren en varios aspectos de las entregadas por las adolescentes y jóvenes. Si para las primeras, los(as) hijos(as), la dependencia económica serían los principales motivos para permanecer en una relación de violencia. Estas justificaciones no se aplicarían a las mujeres no casadas (mayoritariamente jóvenes y adolescentes) (SERNAM, 2003). Sin embargo, las creencias románticas asociadas a la idea que «el matrimonio es para toda la vida» por parte de las mujeres adultas (SERNAM, 2003) y una representación tradicional del amor romántico por parte de las jóvenes y adolescentes (Fernet, 2005) expondría una convergencia en torno al género.

Por otro lado, diversos estudios mencionan la escasa experiencia en el plano de las relaciones amorosas; un repertorio más exiguo para resolver los conflictos de parejas y la presión de pares, como factores que podrían influenciar una mayor tolerancia hacia la violencia por parte del grupo de menor edad (Shorey et al., 2008, Lavoie et al, 2000). 
... Factores de riesgo...

La literatura examinada está lejos de formar un consenso para determinar la existencia de precursores de la violencia en ambos grupos (Vézina et al., 2007; Lewis y Fremouw, 2001; Sugarman et al., 1989; Organización Mundial de la Salud, OMS, 2002). Expondremos algunos factores de riesgo, escogidos para establecer semejanzas como distinciones en ambos grupos.

En relación a factores sociodemográficos, se observa el aumento de la edad, ligado al establecimiento de una relación más formal como un factor de mayor riesgo para vivir violencia. Los estudios de prevalencia arrojan un mayor porcentaje y severidad en parejas que han establecido relaciones con un mayor compromiso («pololeo largo», matrimonio o convivencia) en comparación con relaciones amorosas que no conllevan una larga data o un compromiso mayor (Roscoe et al.,1985a; Stets et al., 1989; DOMOS, 2010; INJUV, 2012). No obstante, la falta de experiencia amorosa, ligada a una edad temprana, también es considerado como un factor de riesgo, ya que se contaría con menos recursos para enfrentar conflictos de este tipo (Makepeace, 1989; Hird, 2000; Henton et al., 1983; SERNAM, 2010).

En cuanto a factores individuales, como ya hemos señalado el género se reconoce como un factor de riesgo importante. Las jóvenes y mujeres adultas, son las principales víctimas de violencia, sobre todo de la violencia severa con consecuencias más graves como indicábamos más arriba. Por su parte, las creencias y las actitudes «más románticas o más tradicionales» hacia los roles de género y las relaciones amorosas, influirían en una mayor tolerancia ante situaciones de violencia y en la decisión de mantener dichas relaciones por parte de las adolescentes y las mujeres adultas. En el caso de hombres adultos y los adolescentes, una concepción jerárquica respecto de los roles de género así como la noción que las relaciones de pareja serían hostiles o desiguales, se mencionarían como actitudes que justificarían la violencia ejercida. (Sears et al., 2007; O'Keefe et al., 1998; De Maris, 1987; Loseke et al. 2005). Podemos señalar entonces, que este factor (creencias y actitudes) operaría de manera diferente según el género, en donde las relaciones estereotipadas: idealizadas para las mujeres y desiguales para los hombres, justificaría aceptar la violencia en las primeras y ejercerla en los segundos.

Respecto de factores relacionales, recurrentemente se menciona en la literatura las experiencias de violencia durante la infancia; es 
decir, malos tratos vividos durante la niñez, exposición a la violencia intrafamiliar o experiencias de abuso sexual, como un factor de riesgo significativo para establecer relaciones de violencia en etapas posteriores. Dichas experiencias provocarían normalizar la violencia, minimizarla o tener actitudes más tolerantes (Fernet, 2005; Roscoe et al., 1985; Sears et al., 2007; Lehrer et al, 2010; Vézina et al., 2007; Barter, 2009, Sugarman et al., 1989; Roscoe et al., 1985a; Aguayo, Correa y Cristi, 2011).

No obstante lo anterior, existen controversias cuando se intenta establecer un vínculo entre la violencia ocurrida en las primeras relaciones amorosas y aquellas establecidas en el período de adultez. Algunos autores indican que aquellos(as) adolescentes que han experimentado violencia en sus relaciones amorosas estarían más expuestos(as) a vivir violencia en la etapa adulta, es decir, podríamos hablar de una continuidad de la violencia en estas dos etapas de vida (Roscoe et al., 1985a; Roscoe et al., 1985b). Otros autores, recalcan que la violencia en la adolescencia y la violencia en la adultez son de una etiología diferente, no siendo posible determinar que la violencia experimentada durante la adolescencia podría significar una mayor probabilidad para establecer relaciones de violencia en la etapa adulta (Makepeace, 1989; Riggs et al., 1989; Carlson, 1987). Como señala De Maris (1987), los conflictos, los factores de estrés y la dinámica vinculada a ambos grupos no son asimilables, por ende, no sería posible analizar la violencia — en ambas etapas - como un continuum.

Finalmente, en cuanto a factores sociales o de contexto, se menciona como una divergencia importante la influencia del grupo de pares en adolescentes. Estudios indican que si el grupo de pares posee una aceptación a la violencia es posible sostener que él o la adolescente la podría ejercer o tolerar. Por el contrario, si el grupo de pares rechaza el ejercicio de prácticas violentas, este podría convertirse en un factor de protección o de inhibición frente a quienes la pudiesen sufrir o ejercer (Cloutier et al., 2008; Lavoie, et al., 2000; Sears et al., 2007; Vézina et al., 2007). En la adultez, la influencia de pares no tendría el mismo impacto en sus vidas y decisiones, no siendo abordado en la literatura con la importancia que se le da en la adolescencia. Acorde a lo anterior, el uso de internet, la exposición a una publicidad sexualizada y a la pornografía han sido documentados como factores de riesgo que tendrían un impacto particular entre los(as) adolescentes debido a la etapa de mayor vulnerabilidad emocional en la que se encontrarían (Lavoie et al., 2000). 


\section{PUNTO DE VISTA DE ADOLESCENTES EN TORNO A LA VIOLENCIA EN LAS RELACIONES AMOROSAS DE ADULTOS Y JÓVENES}

Algunas de las diferencias en torno a la violencia entre parejas de adultos y parejas de jóvenes son abordadas por los(as) participantes de los grupos de discusión. Se exponen cuatro puntos que permiten abordar el objeto de nuestro artículo desde la visión de los(as) propios participantes.

\section{a) La violencia en parejas de jóvenes existe, pero es más grave en adultos...}

La mayoría de los(as) participantes consideran que la violencia existe al interior de las parejas adolescentes, no obstante, es un problema considerado más grave en adultos, debido a que estos(as) estarían expuestos(as) a situaciones de estrés y conflictos más complejos a resolver (trabajo, hijos(as), dinero). Por otro lado, la larga data de sus relaciones y los factores de compromiso (familia, aspectos legales, hijos(as) pudiesen dificultarles el término de la relación y por ende vivir situaciones más severas de violencia. En cambio, los conflictos que viven las parejas de adolescentes (celos, engaños, inseguridades) serían considerados como menos graves, lo que les llevaría - según su punto de vista - a no estar expuestos(as) ni a ejercer gestos severos de violencia. Por otro lado, considerar sus relaciones como espacios de aprendizaje y experimentación en donde no existen vínculos importantes que impidan a sus miembros poner fin a ésta, explicaría la corta durabilidad de sus relaciones.

...el nivel de estrés de (un) adulto es mayor, entonces es para desquitarse a veces... yo cuando veo adolescentes, no se da lo mismo... mayoritariamente [en jóvenes] es como violencia psicológica (Joaquín, 18 años).

...lo que pasa es que igual era distinto porque así como decían que las relaciones de los jóvenes como que si a ti te molesta algo era como llegar y ... terminar, en cambio sí son más grande están casados es como... no es tan fácil llegar y terminar (Bárbara, 15 años).

Otra diferencia indicada por los(as) participantes dice relación con el grado de madurez, es decir, los(as) adolescentes se consideran a sí mismos(as) como más impulsivos(as), menos maduros(as) o en una 
etapa de aprendizaje que les llevaría - frente a conflictos en la pare$\mathrm{ja}-\mathrm{a}$ reaccionar irreflexivamente utilizando gestos violentos. Su inexperiencia amorosa se consideraría como un obstáculo para distinguir la violencia vivida, lo que se complejiza al experimentar gestos más sutiles de violencia (control, chantaje, celos). Varios de los(as) participantes señalan que la madurez adquirida con el tiempo les permitiría enfrentar los problemas sin el uso de la violencia.

... generalmente los adultos son más maduros que los adolescentes, entonces no actúan bajo los impulsos... en cambio un adolescente... lo que va hacer si ve a su polola que lo está cagando, va a reaccionar altiro, no lo va a pensar dos veces, pero el adulto no es así (Rodrigo, 16 años).

\section{b) La violencia de antes era peor, aunque ahora vivimos en una sociedad muy desconfiada...}

Otra divergencia entre ambas generaciones dice relación con la época en la cual ambas viven. La gran parte de los(as) participantes reconocen la existencia de cambios culturales que han marcado la sociedad chilena, distinguiendo una época en la que las mujeres se encontraban en una posición de inferioridad y desvalorización en relación a los hombres.

Los estereotipos característicos de una época «machista» reproducirían el binomio mujer/víctima-hombre/agresor, lo que se traduciría en el ejercicio de roles de género rígidos practicados principalmente en parejas adultas. Esta representación explicaría — según algunos(as) participantes - la unidireccionalidad de la violencia en parejas adultas, es decir, la violencia ejercida principalmente desde los hombres hacia las mujeres.

...en el caso de los hombres hacia las mujeres... puede que el hombre también sea controlador y probablemente la mujer no trabaje, que es lo que se da más a menudo, que la mujer como que es más ama de casa... (Camelia, 15 años).

Por el contrario, una gran parte de los(as) participantes indican que la «mutualidad» de la violencia caracterizaría las experiencias de los(as) jóvenes. Es decir, tanto chicas como chicos ejercerían violencia hacia sus enamorados(as). Según estos(as) la sociedad chilena sigue siendo machista, por tanto la violencia ejercida por los hombres hacia las mujeres continua considerándose más grave. Sin embargo, el uso de la 
violencia por parte de las mujeres jóvenes hacia sus pololos sería considerada como bastante común.

...yo creo que hay menos diferencias porque en ambos casos [chicos y chicas] se tratan mal, en ambos casos se pueden golpear, en ambos casos se pueden decir malas cosas (María Carolina, 16 años).

...o sea hubo un tiempo no sé si todavía pasará que la mujer se dejaba abusar porque era una sociedad tan machista, que la mujer estaba criada para... siempre ser abusada por el hombre, en cambio ahora la mujer se hace respetar y eso también lleva (a) mucha violencia, muchas veces por parte de la mujer, la mujer se hace respetar frente al hombre y viene esta como ola de feminismo y la mujer (se) siente como no sé... poderosa y se tiene que hacer respetar (Flavia, 16 años).

Algunos(as) participantes identifican diferencias en las relaciones de pareja establecidas por generaciones anteriores a ellos(as) y las que establecen las generaciones actuales. Viven en una sociedad más abierta respecto de las relaciones amorosas, pero al mismo tiempo consideran que resulta mas difícil confiar en los(as) demás. En este sentido, si bien consideran que los avances tecnológicos han contribuido a facilitar las relaciones, la gran mayoría sin embargo, considera que las «redes sociales» generan grandes conflictos al interior de las parejas.

....ahora como que ya nadie confía en nadie, entonces tiene que andar revisando tiene que andar abusando de la confianza del otro y ver todo lo que hace, yo creo que en ese sentido nosotros (los jóvenes) estamos más perjudicados que las generaciones anteriores (Fernanda, 16 años).

...es como que todo el mundo se entera que, aparte por facebook se generan muchos problemas, por ejemplo si un tipo le pone un comentario así como oh que te ves bonita, es como un comentario, un coqueteo y ahí (uno) se pone celoso... (Adolfo, 16 años).

c) Eso no es violencia, es un juego...

El carácter subjetivo de la violencia y la importancia del contexto para interpretar los gestos es expuesto por algunos(as) participantes quienes considerarían que ciertos gestos no serían interpretados como violencia, sino como parte de un juego que se establece con personas con las que se tiene gran confianza: amigos(as) y pareja. En este sentido, la importancia dada a la fuerza física para definir un gesto como violen- 
to, el asociar la violencia como una práctica conforme a un estereotipo masculino y el escaso impacto del gesto físico por parte de las adolescentes explicarían - según algunos(as) participantes - una cierta tolerancia social a la violencia ejercida por éstas.

...eso pasaría... si estás pololeando obviamente hay harta confianza entonces no sé un golpecito así... si porque hay parejas que lo hacen como de juego (Joaquín, 18 años).

...es producto es producto de la sociedad porque yo como que siempre pensaba que eh es justificable [violencia de parte de la mujer] pero ahora como que estoy analizándolo y pucha es violencia igual y es producto de la sociedad en que estamos, hasta las películas, las novelas se ve cuando le pegan la cacheta [al hombre] entonces es como algo social, se ve normal pero igual es violencia porque es un golpe (Valeria, 16 años).

...la sociedad es más machista, entonces tiene la visión machista de que el hombre por así decirlo, si un hombre le levanta la voz (a una mujer) por así decirlo ya es maltrato, que una mujer lo haga no es tan así (Bastían, 16 años).

Las particularidades asociadas a la violencia que viven los(as) jóvenes en sus relaciones de pareja influirían en la noción que elaboran de ésta, así como en la posibilidad de identificarla. Muchos de los gestos identificados como sutiles de la violencia e identificados por los(as) participantes como más comunes en sus experiencias - chantaje, celos, manipulación, entre otros- son justamente los más difíciles a reconocer.

...yo creo, lo que pasa es que los adolecentes no tienen claro lo que es la violencia, entonces no saben cómo detectarla (Nina, 15 años).

\section{d) Ahora se habla más de la violencia, pero a mí no me llega...}

Si bien los(as) participantes reconocen avances en materia de sanción y prevención de la problemática, paralelamente, exponen un alto desconocimiento de las acciones dirigidas hacia ellos(as). Dos posibles entradas para abordar dicho desconocimiento: Por un lado, la respuesta remite a una real desinformación frente a las actuales acciones que en esta materia se vienen desarrollando desde distintas esferas institucionales. Por otro, la respuesta exhibe el estado actual del abordaje reflejando la clara ausencia de acciones elaboradas hacia este grupo en particular. 
Ambas entradas sin embargo, reflejan una ruptura en la relación entre las estrategias y medios utilizados y los(as) sujetos(as) a los cuales están focalizadas dichas acciones. El diálogo que debiese existir entre discurso construido desde una acción planificada (en este caso, aquellas tendientes a la prevención de la violencia en las relaciones amorosas en jóvenes) y la apropiación que los(as) sujetos(as) realizan de estos discursos, no estaría totalmente presente. Por otro lado, cuando los(as) participantes declaran conocer alguna estrategia de prevención identifican mayoritariamente acciones destinadas a las familias, a las víctimas (mujeres), con énfasis en la violencia física y a parejas estables y/o de adultos. Aquellos(as) jóvenes que no viven la problemática señalan que la actual estrategia de prevención no les llama la atención.

...es menos que antes porque ahora si se han fijado, hay puras campañas de no a la violencia, personas famosas o todo está ya relacionado a que no haya violencia, a denuncie si te maltratan... cada vez se está haciendo conciencia de que... no sé antes era como un tabú (Iván, 15 años).

...he buscado, he preguntado y no hay mucha información o que se trabaje sobre el tema aplicándolo en alumnos, ya sea de media o de básica como para que lo apliquen en su vida, o sea, no hay como interés sobre el tema... (Pedro, 16 años).

[en relación a una campaña de prevención] si yo no he golpeado a (una) mujer, no me tendría por qué llegar a mí poh, pero si yo lo he hecho ahí (sí)... (Emiliano, 15 años).

\section{A MODO DE CONCLUSIÓN}

Las distinciones en torno a la violencia en parejas de adolescentes y parejas de adultos expuestas por la literatura analizada y por las opiniones de los(as) participantes del estudio, permiten establecer un punto de partida para considerar la violencia en parejas de adolescentes como una problemática particular que invita a pensar la violencia íntima desde nuevas categorías.

a) Un primer aspecto a considerar dice relación con: la invisibilidad conceptual

Que se ha otorgado a este tipo de violencia. La opción del Estado chileno de utilizar el concepto de «violencia intrafamiliar» tiene como 
consecuencia desatender todas aquellas situaciones de violencia ocurridas en relaciones amorosas que se encuentren fuera del contexto familiar y de concebir a este segmento juvenil como sujetos(as) que viven violencia sólo desde su posición de hijos(as) y no como individuos(as) que establecen relaciones amorosas y que pueden experimentar violencia.

Como hemos señalado el concepto que se utiliza para nombrar una problemática o para representar una realidad tiene repercusiones a su vez en el orden material; es decir, constatamos que la invisibilidad se expresa, por un lado, en una ley que solo sanciona la violencia al interior de la familia y en segundo lugar, en un Plan de prevención que no describe en específico la problemática, pero que sin embargo, diseña algunas acciones para prevenirla. Las particularidades expuestas permiten sostener estar en presencia de un fenómeno que se distingue de las experiencias de violencia en parejas adultas. En este sentido, la etapa de vida, la percepción sobre la época en la que viven, la variabilidad en sus relaciones, los conflictos que les afectan, el tipo de violencia y las manifestaciones identificadas, los motivos y las significaciones dadas a la violencia. Constituyen un sello que marca una problemática y que aún de los estudios realizados en Chile, no ha significado modificar las nociones que desde el Estado y desde los instrumentos legales como de planificación existen para abordarla.

\section{b) Un segundo aspecto apunta: la noción de adolescencia}

En este sentido, considerarla fundamentalmente como un período de storm and stress en que se transita hacia un estado de calma representado por la adultez en donde «todo se resuelve hasta que maduren», entorpece la búsqueda de nuevos modelos para comprender y prevenir el problema considerando el punto de vista de los(as) adolescentes. Si la adolescencia es considerada como una etapa de vida caracterizada solamente por conflictos, cambios y experimentaciones, probablemente sus relaciones se representarán como frágiles, poco durables y poco significativas, entonces, los problemas ligados a este tipo de vinculos podrían ser considerados poco importantes o pasajeros.

El reconocimiento social exclusivo a las relaciones «tradicionales» de pareja (pololeo, noviazgo, matrimonio, convivencia), podría constituir un factor limitante para identificar problemas como la violencia en las relaciones amorosas. Especialmente en aquellas relaciones de adolescentes que se encuentren en una especie de zona gris (frecuentacio- 
nes o amistades sexuales) que no son asimilables a las relaciones tradicionales.

\section{c) Un tercer elemento dice relación con: la necesidad de profundizar}

En aquellas particularidades que distinguen a la violencia en las relaciones amorosas de los(as) adolescentes y la de los adultos. Entonces, explorar sus trayectorias amorosas especialmente aquellas que difieren cualitativamente de las relaciones tradicionales, ayudaría en la comprensión de los códigos que orientan las practicas adolescentes. Resultaría pertinente también considerar los factores de conflictos que les afectan (celos, por ejemplo), más que centrarse solo en las dinámicas de parejas con el riesgo de asimilarlas a las relaciones tradicionales de adultos.

Explorar la significación de la mutualidad de la violencia de tal forma de aproximarse a comprender como ésta se expresa en parejas de adolescentes y jóvenes, más allá de sostener simplemente que se ejerce por igual en chicos y chicas (simetría). Indagar en la violencia ejercida desde las adolescentes y la llamada tolerancia social que impediría reconocerla, así como averiguar sobre las experiencias de los adolescentes frente a la violencia ejercida por sus pololas. Examinar los gestos más comunes que se clasificarían como «violencia leve», así como el concepto de víctima y la posibilidad de sostener que el uso de la violencia desde las adolescentes podría expresar una forma de empoderamiento y de resistencia, cuestionando el lugar de subordinación tradicionalmente asignado al género femenino dentro de la violencia de pareja.

Considerar las nociones que los(as) adolescentes elaboran de igualdad/desigualdad, poder/subordinación, entre otras permitiría repensar las categorías tradicionalmente utilizadas y construir un marco teórico que considere los cambios culturales que caracterizan el contexto en el cual los(as) adolescentes viven. Un marco que incorporase las representaciones conservadoras ancladas en la cultura chilena o como lo han identificado los(as) propios(as) adolescentes «el machismo« que aún existe en Chile.

Los(as) adolescentes son influenciados directamente por el contexto en el que viven, ellos(as) expresan en sus opiniones la identificación con una generación que se diferencia de las anteriores y que debe hacer constantes esfuerzos por reinventarse, por distanciarse de este- 
reotipos y creencias que les impiden construir relaciones amorosas sanas que puedan vivir conflictos pero no violencia. Por tanto, el análisis del contexto permitiría también reconocer los elementos que los(as) adolescentes tienen a disposición para construir sus identidades de género, conformar sus actitudes y reforzar prácticas abusivas o igualitarias en sus relaciones amorosas. Si consideramos que las experiencias amorosas que establecen los(as) adolescentes pueden ser intensas y dejar una huella en el curso de su vida, en donde los comportamientos que se consolidan en esta etapa pueden crear habitudes durables, principalmente en las relaciones hombres/mujeres, se torna imperioso considerarla como un fenómeno que no es posible incluirlo como una problemática familiar y pensar estrategias de prevención que consideren las particularidades de sus experiencias.

QUÉBEC (CANADÁ), FEBRERO 2015

RECIBIDO: ABRIL 2015 ACEPTADO: AGOSTO 2016 


\section{REFERENCIAS BIBLIOGRÁFICAS}

Aguayo, F., P. Correa y P. CRISTI (2011): Encuesta IMAGES Chile Resultados de la Encuesta Internacional de Masculinidades y Equidad de Género. Santiago: CulturaSalud/EME.

AGUIRRE, ANA MARIA y M. INFANTE (1997): «Violencia prematrimonial: Un estudio exploratorio en universitarios». Revista Última Década Nº. Valparaíso: Ediciones CIDPA.

Arriaga, Ximena y VANGIE FosheE (2004): «Adolescent Dating Violence. Do Adolescents follow in their Friends', or their Parents', Footsteps?» Journal of interpersonal violence, 19(2). Beverly Hills, CA: Sage publications.

BARTER, Christine (2009): «In the name of love: Partner Abuse and Violence in Teenage Relationships». British Journal of Social Work, 39. London: British Association of Social Workers.

BARTER, CHRISTINE, MElANIE MCCARRY, DAVID BERRIDGE y KATHY Evans (2009): Partner exploitation and violence in teenage intimate relationships. London: University of Bristol and the NSPCC.

Breinbauer, Cecilia y Matilde Maddaleno (2005): Youth: Choices and Change. Promoting Healthy Behaviors in Adolescents. Washington, DC: Pan American Health Organization.

CARAbineros de ChILE (2013): Sistema AUPOL. Registro Denuncias de Violencia intrafamiliar (2005-2013). www.carabineros.cl.

CÁRCAMO, LUIS y FELIPE NESBET (2008): «La generación messenger. Relevancia de la mensajería instantánea en la adolescencia chilena». Revista Última Década No28. Valparaíso: Ediciones CIDPA.

CARLSON, BONNIE (1987): «Dating violence: A Research Review and Comparison with Spouse Abuse». Social Casework. 68(1). Bruxelles: Éd C.O.M.T.S.

CASTElls, MANUEL (2000): La era de la información: economía, sociedad y cultura. México: Siglo XXI.

Chung, Donna (2005): «Violence, Control, Romance and Gender Equality: Young Women and Heterosexual Relationships». Women's studies international forum, 28. Oxford; New York: Pergamon.

Cloutier, RICHARD y SYLVIE DRAPEAU (2008): Psychologie de l'adolescence. $3^{\circ}$ edición. Montréal: Gaëtan Morin.

CORPORACIÓN CENTRO DE DESARROLLO DE LA MUJER (DOMOS) (2010): Estudio exploratorio: Violencia hacia las jóvenes en relaciones amorosas o de parejas. Santiago de Chile.

DAMANT, DOMINIQUE Y FRANCOISE GUAY (2005): «La question de la symétrie dans les enquêtes sur la violence dans le couple et les relations amoureuses». The Canadian Review of Sociology and Anthropology, 42(2). Toronto: University of Toronto. 
DE MARIS, ALFRED (1987): «The Efficacy of a Spouse Abuse Model in Accounting for Courtship Violence». Journal of family issues, 8(3). Newbury Park, Calif.: Sage Publications.

DIVISIÓN DE SEGURIDAD PÚBLICA DEL MINISTERIO DEL INTERIOR (2012): Encuesta Nacional de victimización por violencia intrafamiliar y delitos sexuales. Santiago. www.interior.gob.cl.

FERnET, MYLENE (2005): Amour, Violence et adolescence. Québec. Presses de l'Université du Québec.

- Martine Hébert, Mélanie St-Hilaire, Martin Blais, Sophie Gasco y HÉlene MANSEAU (2014): En M. Rinfret-RAYNOR, E. LESIEUX, M. COUSINEAU, S. GAUTHIER y E. HARPER (editores): Violence envers les femmes. Réalités complexes et nouveaux enjeux dans un monde en transformation. Québec: Presses de l'Université du Québec.

FosheE, VANGIE (1996): «Gender Differences in Adolescent Dating Abuse: Prevalence, Types and Injuries». Health Education Research, 11(3). Oxford; Washington: IRL Press.

K. BAumAN, F. Linder, J RicE y R. Wilcher (2007): «Typologies of Adolescent Dating Violence». Journal of Interpersonal Violence, 22 (5), Beverly Hills, CA: Sage publications.

Gagné, Marie-Helene, Francine Lavoie y Martine Hébert (1994): «La Violence sexuelle dans les fréquentations chez un groupe d'adolescents et d'adolescentes». Revue Sexologique, 2(1). Montréal: Éditions I.R.I.S.

GIDDENS, ANTHONY (1995): La transformación de la intimidad: Sexualidad, amor y erotismo en las sociedades modernas. Madrid: Cátedra.

Henton, June, Cate Rodney, James Kival, Sally Lloyd y Scott CHRISTOPHER (1983): «Romance and Violence in Dating Relationships». Journal of Family Issues, 4(3). Newbury Park, Calif.: Sage Publications.

HIRD, MYRA (2000): «An Empirical Study of Adolescent Dating Aggression in the UK». Journal of Adolescence, 23. London; New York: Published for the Association for the Psychiatric Study of Adolescents by Academic Press.

INE (2011): Estadísticas demográficas. Santiago: INE.

INJUV (1994): Primera encuesta de juventud. Santiago: INJUV.

- (2010): Sexta encuesta de juventud. Santiago: INJUV. (2012): Séptima encuesta de juventud. Santiago: INJUV.

ISMAIL, FARAH, HELENE BERMAN y CATHERINE WARD-GRIFFIN (2007): «Dating Violence and Health of Young Women: A Feminist Narrative Study». Health Care for Women International, 28. Washington, DC: Hemisphere Pub. Corp.

JoHnSON, Michael (1995): «Patriarchal Terrorism and Common Couple Violence: Two Forms of Violence Against Women». Journal of Marriage and the Family. Menasha, Wis: National Council on Family Relations. 
(2008) «A Typology of Domestic Violence: Intimate Terrorism, Violent Resistance, and Situational Couple Violence». Hanover: University Press of New England.

Lavoie, Francine, Line Robitaille y Martine Hébert (2000): «Teen Dating Relationship and Aggression: An Exploratory Study». Violence against Women, 6(1). Thousand Oaks, CA: Sage Periodicals Press.

LECCARDI, CARMEN y CHARLES FEIXA (2011): «El concepto de generación en las teorías de juventud». Última Década N³4. Valparaíso: Ediciones CIDPA.

LEHRER, JOCELYN, EVELYN LEHRER y ZHENXIANG ZHAO (2010): «Physical dating Violence Victimization in College Women in Chile». Journal of Women's Health, 19(5). New York: Mary Ann Liebert, Inc.

LESIEX, ELISABETH, MARYSE RINFRET-RAYNOR y NORMAND BRODEUR (2014): «Le développement des services d'aide en maison d'hébergement pour femmes victimes de violence conjugale au Québec, de 2004 à 2009». En M. Rinfret-RAYNOR, E. LeSIEX M. COUSINEU, S. GAUTHIER y E. HARPER (editores): Violence envers les femmes. Réalités complexes et nouveaux enjeux dans un monde en transformation. Québec: Presses de l'Université du Québec.

Lewis, SARAH y WiLliam Fremouw (2001): «Dating Violence: A Critical Review of the Literature». Clinical Psychology Review, 21(1). New York: Pergamon Press.

LOSEKE, DONILEEN Y DEMIE KURZ (2005): «Men's Violence Toward Women is a the Serious Social Problem». En D. LOSEKE, R. GElles y M. CAVAnaugh (editores): Current Controversies of Family Violence. Thousand Oaks, CA: SAGE Publications.

MAKEPEACE, JAMES (1981): «Courtship Violence among College Students». Family Relations, 30(1). Minneapolis, Minn: National Council on Family Relations.

(1989): «Dating, Living Together, and Courtship Violence». En M. A. PIROG-GoOd y J. E. STETS (editores): Violence in Dating Relationships. Emerging Social Issues. New York: Praeger.

MOLIDOR, CHRISTIAN y RICHARD M. TOLMAN (1998): «Gender and Contextual Factors in Adolescents Dating Violence». Violence against Women, 4(2). Thousand Oaks, CA: Sage Periodicals Press.

O’KeEFe, Maura y Laura Treister (1998): «Victims of Dating Violence Among High School Students: Are Predictors Different for Males and Females?»Violence Against Women, 4(2). Thousand Oaks, CA: Sage Periodicals Press.

OMS (2002): Informe sobre la salud en el mundo. Reducir los riesgos y promover una vida sana. Washington, DC: Organización Mundial de la Salud.

PNUD (2006): Desarrollo humano en Chile. Las nuevas tecnologías: ¿un salto al futuro? Santiago de Chile. Programa de Naciones Unidas para el Desarrollo (PNUD). 
(2010): Desarrollo humano en Chile. Género: los desafíos de la igualdad. Santiago de Chile: PNUD.

PRÓSPERO, MOISÉS (2007): «Young Adolescent Boys and Dating Violence: The Beginning of Patriarchal Terrorism?» Journal of Women and Social Work, 22(3), New York: Feminist Press.

RED CHILENA CONTRA LA VIOLENCIA DOMÉSTICA Y SEXUAL (2014): Violencia extrema hacia las mujeres en Chile (2010-2012). Santiago de Chile.

REPÚBLICA DE CHILE (2005): Ley No 20.066 publicada en Diario Oficial 7 octubre 2005.

(2010): Ley No20.480 publicada en Diario Oficial 18 diciembre 2010.

RIGGS, DAVID y DANIEL O'LEARY (1989): «A Theorical Model of Courstships Aggresion». M. A. PIROG-GoOD y J. E. STETS (editores): Violence in Dating Relationships. Emerging Social Issues. New York: Praeger.

Roscoe, BRUCE y NANCY BENASKE (1985a): «Coursthip Violence Experienced by Abused Wives: Similarities in Pattern of Abuse». Family relations, 34. Minneapolis, Minn: National Council on Family Relations.

- y JOHN E. CALLAHAN (1985b): «Adolescents' Self-report of Violence in Families and Dating Relations». Adolescence, 20(79). Roslyn Heights, NY: Libra Publishers.

SEARS, HEATHER; SANDRA BYers, JoHn WhElAN y MARCELlE SAINT-P IERRE (2006): «If it hurts you, then it is not a joke: Adolescents' ideas about girls' and boys' Use and Experience of Abusive Behaviour in Dating Relationships». Journal of Interpersonal Violence, 21(9), Beverly Hills, CA: Sage publications.

— - - y LISA PRICE (2007): «The Co-ocurrence of Adolescent Boys' and Girls' Use of Psychologically, Physically, and Sexually Abusive Behaviours in their Dating Relationships». Journal of Adolescence, 20. London; New York: Published for the Association for the Psychiatric Study of Adolescents by Academic Press.

SERNAM (2003): Análisis de la violencia en las relaciones de pareja entre jóvenes. Santiago: SERNAM.

(2008): «Detección y análisis de la prevalencia de la violencia intrafamiliar en la Región de Antofagasta». Santiago: SERNAM.

(2010a): Registro de femicidios íntimos. Santiago: SERNAM.

(2010b): Investigación exploratoria respecto a la violencia ocurrida durante las relaciones adolescentes. Santiago: SERNAM.

(2012): Plan Nacional de Violencia Intrafamiliar en Chile (Noviembre 2012- Diciembre 2013). Santiago: SERNAM.

2014): Registro de femicidios íntimos. Santiago: SERNAM.

SHOREY, RYAN; TARA CORNELIUS y KATHRYN M.BELL (2008): «A Critical Review of Theoretical Frameworks for Dating Violence: Comparing the Dating and Marital Fields». Aggression and violent behavior, 13. Tarrytown, NY: Pergamon. 
SMEDSLUND, KATJA (2014): «Évaluation de pratiques innovantes en matière de lutte contre les violences conjugales en Allemagne, en Autriche et en Espagne». En M. Rinfret-RAYNOR, E. LesieuX, M. Cousineau, S. GAUTIER Y E. HARPER (editores): Violence envers les femmes. Réalités complexes et nouveaux enjeux dans un monde en transformation. Québec: Presses de l'Université du Québec.

SteT, JAN y MURRAY Straus (1989): «The Marriage License as a Hitting License: A Comparison of Assaults in Dating, Cohabiting, and Married Couples». En M. A. PIROG-Good y J. E. STETS (editores): Violence in Dating Relationships. Emerging Social Issues. New York: Praeger.

Straus, MURRAY (2005): «Women's Violence Toward Men is a Serious Social Problem». En D. LOSEKE, R Gelles y M. CAVANAugh (editores): Current Controversies of Family Violence. Thousand Oaks, CA: SAGE Publications.

SugARMAN, DAVID y GERALD Hotaling (1989): «Dating Violence: Prevalence, Context, and Risk Markers». En M. A. PIROG-GoOD y J. E. STETS (editores): Violence in Dating Relationships. Emerging Social Issues. New York: Praeger.

VÉZINA, JOHANNE y MARTINE HÉBERT (2007): «Risk Factors for Victimization in Romantic Relationships of Young Women». Trauma, violence \& abuse, 8(1). Thousand Oaks, CA: Sage Publications.

Wolfe, David; Katreena Scott, Deborah Reitzel-JaFFe, Carolyne GRASLEY y ANNE-LEE STRAATMAN (2001): «Development and Validation of the Conflict in Adolescent dating Relationships Invetory». Psychological Assessment, 13(2). Arlington, Va.: American Psycholgical Association.

WALKER, LENORE (1979): The battered woman. New York: Harper \& Row. 